\title{
HEAVINESS OF SMOKING
}

\section{AMONG EMPLOYED MEN AND WOMEN IN POLAND}

\section{DOROTA KALETA ${ }^{1}$, PIOTR WOJTYSIAK ${ }^{2}$, BUKOLA USIDAME ${ }^{3}$, ELŻBIETA DZIANKOWSKA-ZABORSZCZYK ${ }^{4}$, ADAM FRONCZAK ${ }^{5}$, PRZEMYSŁAW KORYTKOWSKI ${ }^{6}$, and TERESA MAKOWIEC-DĄBROWSKA ${ }^{7}$}

${ }^{1}$ Medical University of Lodz, Łódź, Poland

Department of Preventive Medicine

${ }^{2}$ County Office, Piotrków Trybunalski, Poland

${ }^{3}$ University of Massachusetts, Boston, USA

Department of Public Policy

${ }^{4}$ Medical University of Lodz, Łódź, Poland

Department of Social and Preventive Medicine

${ }^{5}$ Medical University of Lodz, Łódź, Poland

Department of Biopharmacy

${ }^{6}$ West Pomeranian University of Technology in Szczecin, Szczecin, Poland

Faculty of Computer Science and Information Technology

${ }^{7}$ Nofer Institute of Occupational Medicine, Łódź, Poland

Department of Work Physiology and Ergonomics

\begin{abstract}
Objectives: At least $50 \%$ of smokers die prematurely. Those who smoke heavily are at an increased health risk. The purpose of the current report was to evaluate socio-demographic correlates of heavy smoking among employed men and women. Material and Methods: Data derive from the representative, household study - the Global Adult Tobacco Survey conducted in Poland over the years 2008-2010. Results: Of 14000 households selected for the survey, 7840 sampled individuals completed the interviews. Among 1189 daily smokers, the rate of heavy smokers was $63.5 \%$ in males and $43 \%$ in employed females $(\mathrm{p}<0.001)$. The study showed that age and age at the smoking onset were significantly associated with heavy smoking among both genders. Among males and females the heavy smoking rate was the highest in the subjects that started smoking at the age between 14-17 years compared to those who started smoking at the age $\geq 21$ years (odds ratio $(\mathrm{OR})=3.3,95 \%$ confidence interval $(\mathrm{CI}): 2-5.5, \mathrm{p}<0.001$ and $\mathrm{OR}=2.7,95 \% \mathrm{CI}: 1.4-5.3, \mathrm{p}<0.0001$, respectively). The men with house rules that prohibited smoking with some exceptions were 2.4 times more likely to be heavy smokers in comparison with those having rules which completely prohibited it $(p<0.01)$. The men working in workplaces where smoking was prohibited in all indoor areas were at lower odds of heavy smoking relative to those working in areas where smoking was allowed everywhere $(\mathrm{OR}=0.5,95 \% \mathrm{CI}: 0.3-0.9, \mathrm{p}<0.05)$. Among the men, there was also an association between job features and heavy smoking, which was not observed among the women. Conclusions: These findings should be taken into account while developing tobacco control measures addressed to economically active population.
\end{abstract}

Key words: Smoking, Tobacco, Smoking intensity, Employees, GATS, Poland

Received: August 20, 2014. Accepted: April 13, 2015.

Corresponding author: D. Kaleta, Medical University of Lodz, Department of Preventive Medicine, Żeligowskiego 7/9, 90-752 Łódź, Poland (e-mail: dkaleta@op.pl). 


\section{INTRODUCTION}

According to the most recent data, nearly $20 \%$ of the world's population smoke cigarettes; including about 800 million men and 200 million women [1]. In 2009 smokers consumed nearly 5.9 trillion cigarettes. In 2011, tobacco use killed almost 6 million people, with nearly $80 \%$ of those deaths occurring in low- and middle-income countries [1].

Tobacco use in any form is dangerous and is the single most preventable cause of death. Up to $1 / 2$ of all lifetime smokers will ultimately die of a disease caused by smoking, and men and women with comparable smoking patterns exhibit similar patterns of death. Tobacco use is a major risk factor for death due to heart attacks and strokes.

Moreover, worldwide, smoking causes almost $80 \%$ of male and nearly $50 \%$ of female lung cancer deaths. In 2008 in Poland, tobacco was responsible for $23 \%$ of all non-communicable diseases (NCDs), $90 \%$ of trachea, bronchus and lung cancer. The proportion of deaths attributable to tobacco was close to $31 \%$ in men and $12 \%$ among women aged $\geq 30$ years [2]. Based on the data from 27 countries of the European Union (EU) Peto et al. have concluded that smokers who die at the middle-age as a result of tobacco consumption lose an average of 22 years of life [3]. Even those who die at the age $\geq 70$ as a result of smoking lose on average 8 years of life. Peto et al. estimate that, smokers who die as a result of tobacco consumption die 14 years earlier than people who have never smoked. Expressed in life years, it is calculated that in 2010, about 9.94 million years are lost prematurely in the $\mathrm{Eu}-$ ropean Union countries. Thus, the estimated loss to society caused by premature deaths associated with smoking amounts to a monetized value was of 517 billion euro for the EU, which corresponds to about $4.7 \%$ of the gross domestic product (GDP) [3]. In Poland it was 56183 billion euro, which corresponds to about $10.3 \%$ of the GDP.

Importance of the intensity of smoking should be also underlined. A report by Bronnum-Hansen has indicated that men who smoked heavily had 8 more years of poor health than people who had never smoked [4]. Female respondents who smoked heavily had an average of 12 more years of poor health, in addition to their earlier loss of life. A number of studies have brought to our attention comparable results [5-7].

Tobacco consumption also leads to higher health care costs and decreased productivity due to more cases of absenteeism and premature retirements or deaths [8-12]. Leigh et al. in a study of a cohort of retirees, have found that the number of packs of cigarettes smoked per day was significantly associated with the number of days hospitalized [13]. Hammond has noticed a strong dose-response relationship in a 2-year follow-up of smokers in the American Cancer Society Cancer Prevention Study I [14]. Compared with those who smoked 1-9 cigarettes per day, those who smoked 10-19, 20-39, and $\geq 40$ cigarettes per day had an increased likelihood of hospitalization during the follow-up period of $8.5 \%, 14.6 \%$, and $28 \%$, respectively $[14,15]$. A national study based on the American Productivity Audit data of the U.S. workforce has found that tobacco use was one of the most important variables observed when determining worker lost production time (LPT). Tobacco was more important than alcohol consumption, family emergencies, age or education [16]. Lost production time (LPT) from health conditions increased in relation to the number of smoked cigarettes. Lost production time estimated for workers who reported smoking $\geq 1$ pack of cigarettes per day was $75 \%$ higher than that observed in the case of nonsmoking and exsmoking workers [16].

However, absenteeism represents only a part of the total indirect burden of smoking to employers [9]. It is also possible that, in addition to lost time as a result of illness, smokers are also less productive on the job.

Among individuals with acute or chronic conditions (including smoking related conditions), productivity may decrease because of the employee working while suffering 
from illness symptoms [9]. Moreover, smokers may have additional productivity decrements from losing time taking more breaks for smoking.

In order to decrease premature deaths and smoking related costs for the society there is a need to reduce smoking, especially heavy smoking among overall and economically active population. Workplaces seem to be a suitable environment for implementation of tobacco control programs. Following up on previous reports, the purpose of this study was to evaluate socio-demographic correlates of heavy smoking including job characteristics among employed men and women in order to develop well-tailored, effective tobacco control strategies.

\section{MATERIAL AND METHODS}

Data on the varying smoking levels among the economically active population were derived from the Global Adult Tobacco Survey (GATS). It is a global project developed for systematic monitoring of adult tobacco use worldwide. The Global Adult Tobacco Survey was implemented across 14 mid and low income countries [9,17,18]. The Global Adult Tobacco Survey Poland is a standardized, household, nationally representative survey. It is also a cross-sectional survey presenting results at 1 point in time.

In Poland, the survey population selection process was based on a multi-stage stratified geographically clustered sample of non-institutionalized population aged $\geq 15$ years, including men and women. The Global Adult Tobacco Survey Poland represents all 16 voivodeships in Poland. Subjects who lived in dormitories or students hostels, prisons, nursing homes and other institutions were not included. Data set was provided by the Central Statistical Office. Of 14000 households selected for the survey, 8948 (63.9\%) households and $7840(93.9 \%)$ sampled persons successfully completed the interviews. The total survey response rate was $65.1 \%$. More detailed information on GATS methodology was previously published [19].

\section{Study variables}

In our analysis we focused on daily smokers only. Current daily smoker was defined as a person who smokes regularly, at least 1 cigarette a day. Among daily smokers, we distinguished light to moderate smokers (smoking an average $<20$ cigarettes per day) and heavy smokers (smoking on average $\geq 20$ cigarettes per day).

In addition to gender and age of the respondents, data on the age at the onset of smoking were also included in our analysis. Age at the smoking onset was described as the age at which respondents started smoking on a regular basis ( $<14,14-17,18-20, \geq 21$ years).

Educational level was divided into: primary education, vocational education, secondary education and higher education. Job characteristics classified the subjects as management or co-management in a company or an enterprise, expert, independent professional with high qualifications and higher education, white-collar worker, administrative office staff in a company or an enterprise, trade or services employee, foreman, technician supervising manual workers, skilled worker, non-skilled worker or farm worker. Furthermore, the subjects were classified according to their place of residence - rural or urban area (urban area $<50$ 000, 50 000-200 000, and $>200000$ inhabitants).

Awareness of health consequences of smoking was also analyzed. We categorized our respondents as aware (those who answered "yes" to the question: "Do you think that tobacco smoking causes serious diseases?") and not aware (those who answered "no" and "do not know"). In our analysis we also used the data on the rules regarding smoking at home (smoking is allowed, smoking is prohibited with some exceptions from this rule, smoking is completely prohibited, no rules). Rules regarding smoking in the indoor areas in the workplace were also obtained (smoking is allowed everywhere, smoking is allowed in some indoor areas, smoking is prohibited in all indoor areas, there is no policy). Support for tobacco control policies was classified 
as high, medium, low. Data on the time to the 1st cigarette after waking up (<30 min, $\geq 30 \mathrm{~min}$ ), waking up during the night to smoke ("yes", "no"), attempts to quit during past 12 months ("yes", "no") were also collected.

\section{Statistical analyses}

Statistical associations of particular categories of characteristics in the analyzed groups were assessed with the $\mathrm{Chi}^{2}$ test. Logistic regression model was implemented to evaluate factors associated with heavy smoking among males and females in the following age groups: 26-29, 30$39,40-49,50-59, \geq 60$ years. In the 1st stage, univariate coefficients - odds ratios (OR) of the impact of odd variables on the heavy smoking were calculated. Afterwards, a multi-factorial analysis of the simultaneous effect of all the variables on the odds of heavy smoking was applied. For all analyses, $\mathrm{p}<0.05$ were set as being statistically significant. The evaluation was completed using statistical software package STATISTICA Windows XP version 8.0.

\section{RESULTS}

In GATS Poland, among economically active persons there were 1189 current daily smokers (757 male and 432 female). In this group, the percentage of heavy smokers was $63.5 \%$ among males and $43 \%$ among females $(\mathrm{p}<0.001)$. There were noted some differences in proportions of heavy smoking in selected subgroups of the male and female respondents (Table 1 and 2).

In the male participants aged 26-29 years, the percentage of heavy smokers was the lowest compared to the older age groups, and in this group the percentage of heavy smokers was significantly lower than the percentage of light smokers ( $40 \%$ vs. $60 \%, p<0.001)$. A similar pattern was observed among the women. Higher proportions of heavy than light to moderate smokers was also noted among the male respondents who started to smoke at the age 14$17,18-20$ years, with a diverse relation among the male respondents declaring smoking onset at the age $\geq 20$.
In the case of women, greater proportions of heavy than light to moderate smokers were also noted among the respondents who started to smoke at the age 14-17 years, and the situation was opposite among those who stared to smoke at the age $\geq 20$.

Among the male employees having vocationally and secondary education, proportions of heavy smokers were higher than light to moderate smokers. Other characteristics where differences in the rates of heavy smoking occurred among the male respondents were: place of residence and job features. What is important, among the male employees adopting smoking bans at home and having total smoking ban at work, the proportions of heavy smokers was lower than light to moderate smokers. However, awareness on smoking health consequences and a higher level of support for tobacco control policies were not related to the reduced rates of heavy smokers. In the group of women, within a number of variables, including awareness of health effects of smoking, the rules on smoking at home and work significantly differentiated the percentages of heavy versus light to moderate smokers. In the case of the women aware of smoking health consequences, the rate of heavy smokers was lower than that of light/moderate smokers. In the group of those female respondents who declared that smoking was allowed at their home, the percentage of heavy smokers was significantly higher than the percentage of light/moderate smokers. With the same positive trend as among the male respondents, among the female respondents declaring that smoking is prohibited in all indoor areas in their workplace, the percentage of heavy smokers was lower than the percentage of light to moderate smokers. Detailed characteristic of the study subjects is presented in Tables 1 and 2.

\section{Univariate analysis}

The highest odds of heavy smoking among the economically active male population were within the age group $\geq 60$ (odds ratio $(\mathrm{OR})=5,95 \%$ confidence 


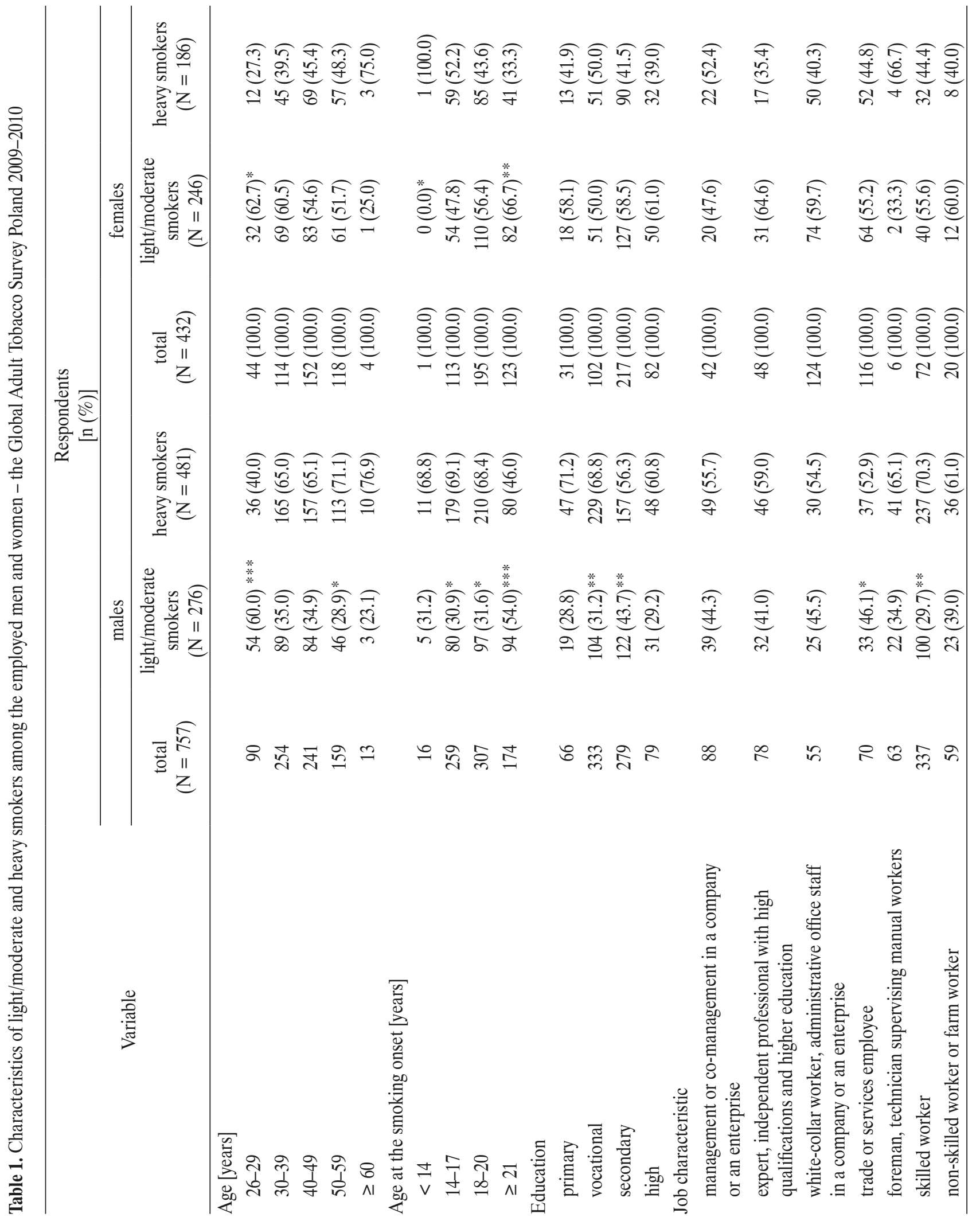








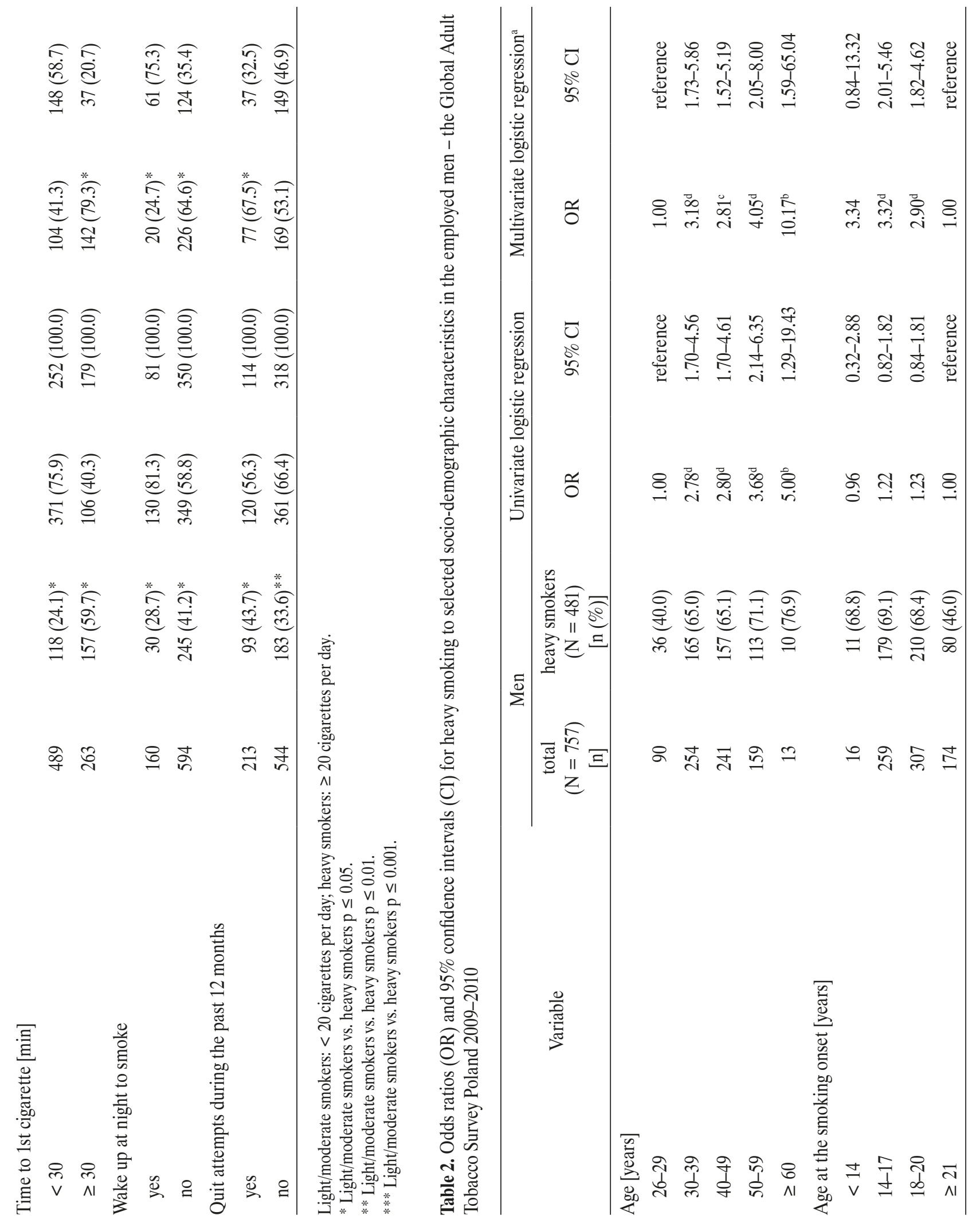


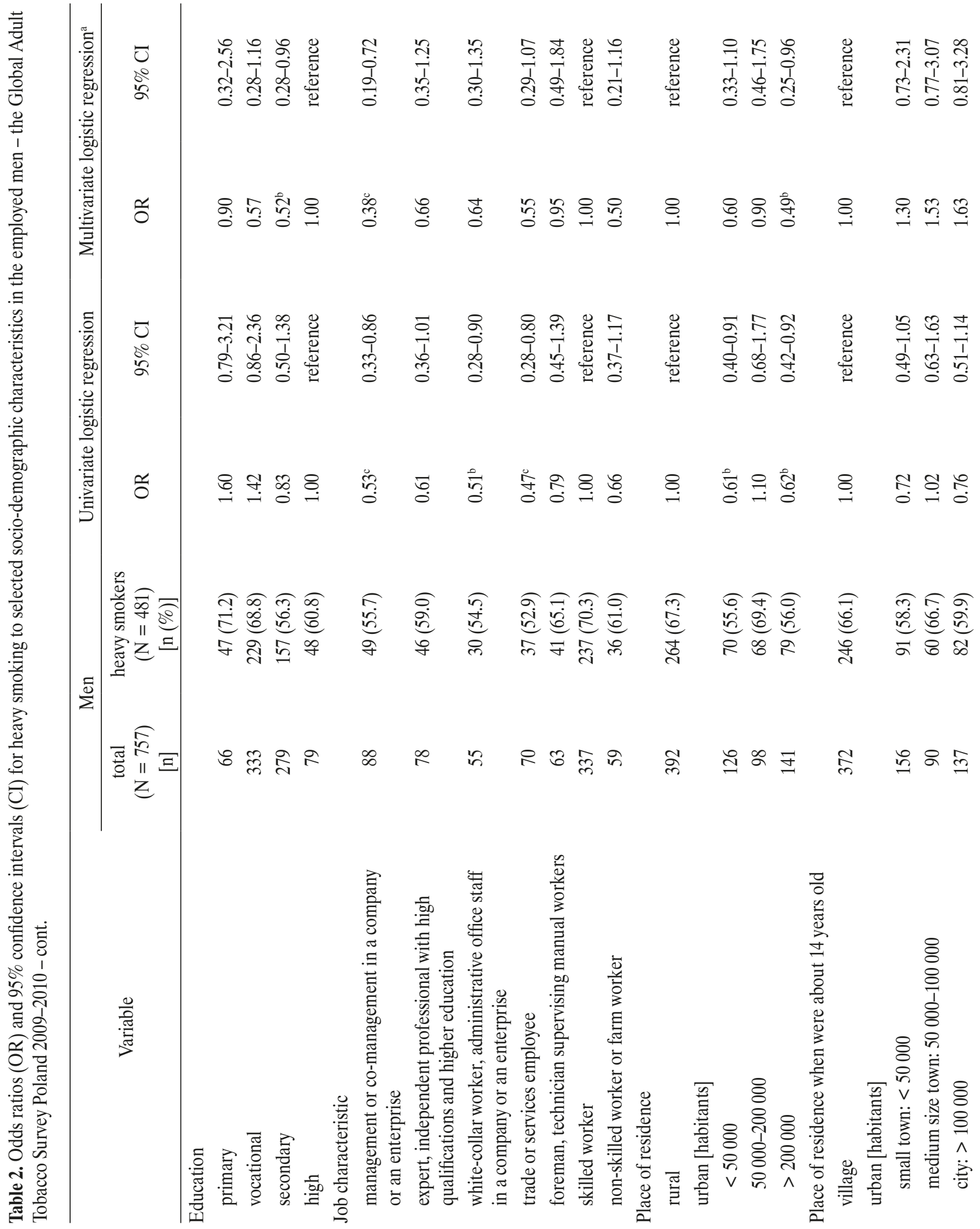




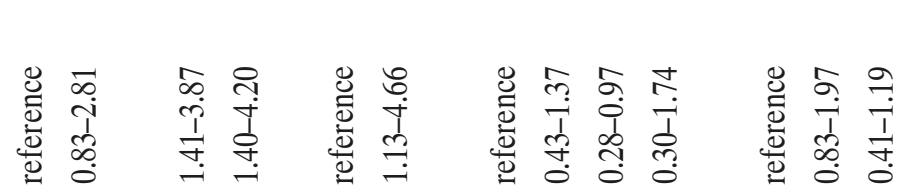

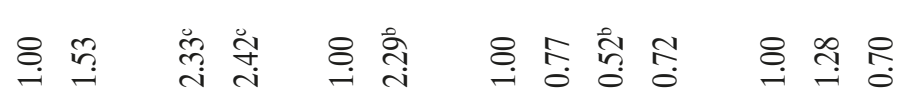

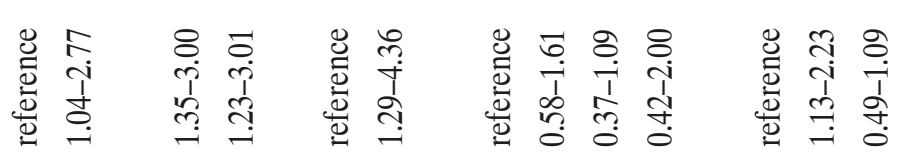

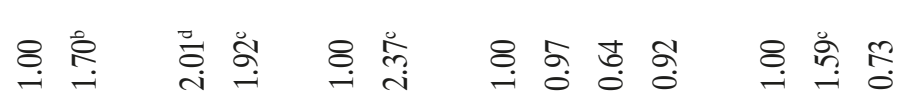

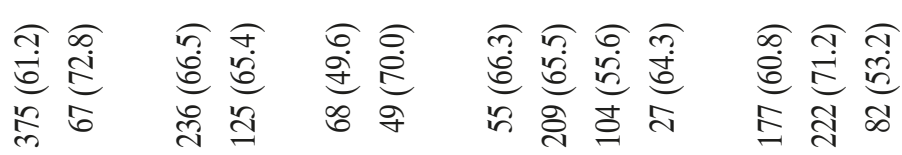

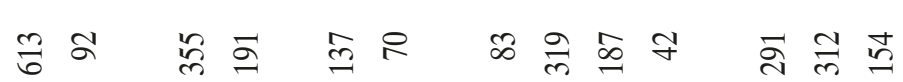

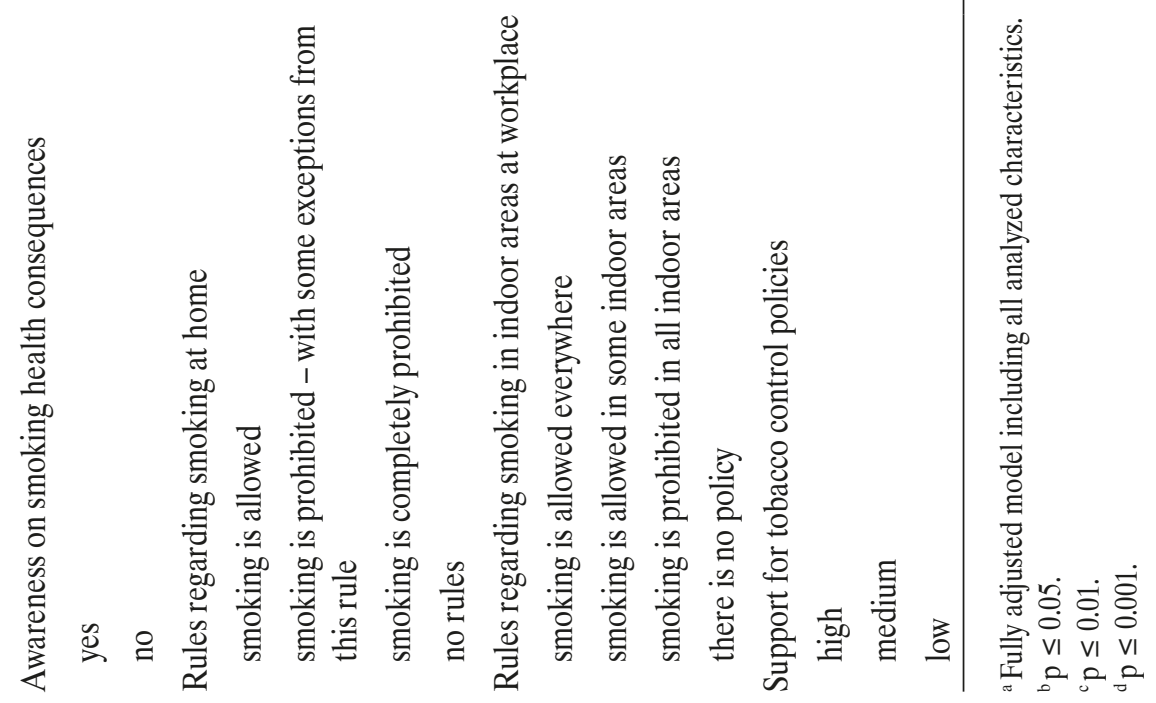


interval (CI): 1.3-19.4, p < 0.05) (Table 1). Job characteristics had an association with heavy smoking among the investigated men. Heavy smokers were less likely to be found among trade or service employees relative to the skilled workers, which was the reference group $(\mathrm{OR}=0.5,95 \% \mathrm{CI}: 0.3-0.8, \mathrm{p}<0.01)$. Working in a management position $(\mathrm{OR}=0.5,95 \% \mathrm{CI}$ : $0.3-0.9$, $\mathrm{p}<0.01)$, or a white-collar position $(\mathrm{OR}=0.5,95 \% \mathrm{CI}$ : $0.3-$ $0.9, \mathrm{p}<0.05$ ) also presented a lower odds of heavy smoking relative to being a skilled worker. The highest percentage of smokers were not likely to be aware of health consequences of smoking $(\mathrm{OR}=1.7,95 \% \mathrm{CI}: 0.9-2.8, \mathrm{p}<0.05)$. The higher heavy smoking odds were more likely to be found among smokers that had no house rules on smoking within home environment compared to those where smoking was totally prohibited $(\mathrm{OR}=2.4,95 \% \mathrm{CI}: 1.3-4.4, \mathrm{p}<0.01)$. With figures similar to that of the studied men, the women who had the highest odds of being heavy smokers were within the 50-59 years age group relative to those who were 20-29 years of age $(\mathrm{OR}=2.5,95 \% \mathrm{CI}: 1.2-5.3, \mathrm{p}<0.01)$. In a similar pattern with the men, majority of the heavy smokers among the women were not likely to be aware of smoking health consequences $(\mathrm{OR}=3.3,95 \% \mathrm{CI}$ : $1.5-7.5$, $\mathrm{p}<0.01)$. The relationship between supporting tobacco policies and heavy smoking shows that the men who supported medium levels of tobacco control policies were at a significant higher odds of heavy smoking relative to those who supported high levels of tobacco control policies $(\mathrm{OR}=1.6,95 \% \mathrm{CI}: 1.1-2.2, \mathrm{p}<0.01)$. Alternatively, there was no significant relationship between the women's support for tobacco control policy and being heavy smokers. Other characteristics, such as job characteristics were not significant among the studied women.

\section{Multivariate analysis}

Results from the multivariate analysis verified some of the information in the univariate section (Tables 2 and 3 ). Being within the age group $\geq 60$, was equivalent to having the highest odds of smoking in the men compared to being between 26-29 years of age $(\mathrm{OR}=10.2,95 \% \mathrm{CI}$ : $1.6-65, \mathrm{p}<0.05)$. Another factor associated with heavy smoking was age at the smoking onset. The odds of heavy smoking were higher among those male respondents that started smoking between the ages of 14-17 compared to those who started smoking after the age of 21 (OR = 3.3, 95\% CI: 2.01-5.46, p < 0.001).

Education was another factor significantly associated with heavy smoking, as the men with secondary education had lower odds of heavy smoking relative to those in high school (OR $=0.5,95 \%$ CI: $0.3-1, p<0.01)$. The men with house rules that prohibited smoking with some exceptions were 2.4 times more likely to be heavy smokers than those with the rules that completely prohibited it $(\mathrm{p}<0.01)$.

The men working in areas where smoking was prohibited in all indoor areas were at a lower risk of heavy smoking relative to those working in areas where smoking was allowed everywhere $(\mathrm{OR}=0.52,95 \% \mathrm{CI}: 0.3-$ $0.9, \mathrm{p}<0.05)$. Among the men, there was also an association between job features and heavy smoking, which was absent among the women. The men who worked in various forms of managerial positions were at a lower risk of becoming heavy smokers relative to the skilled workers, but we did not find such significant associations with other job types (OR $=0.4,95 \%$ CI: $0.2-0.8, \mathrm{p}<0.01)$. The men living in urban areas with a population $>200000$ had significantly lower odds of heavy smoking relative to those living in rural areas (OR $=0.5,95 \% \mathrm{CI}: 2.01-5.46, \mathrm{p}<0.001)$. Some results for the women showed slight differences in comparison to men. For example, being within the age group of 40-49 years was significantly associated with heavy smoking among the women ( $\geq 60$ for men) relative to the age group 26-29 years $(\mathrm{OR}=3.1,95 \%$ CI: $1.3-$ $7.5, \mathrm{p}<0.01)$. Unlike the men, education and job characteristics showed no significant association among the women. House and work rules were also not associated with being a heavy smoker among the women. On the other hand, 


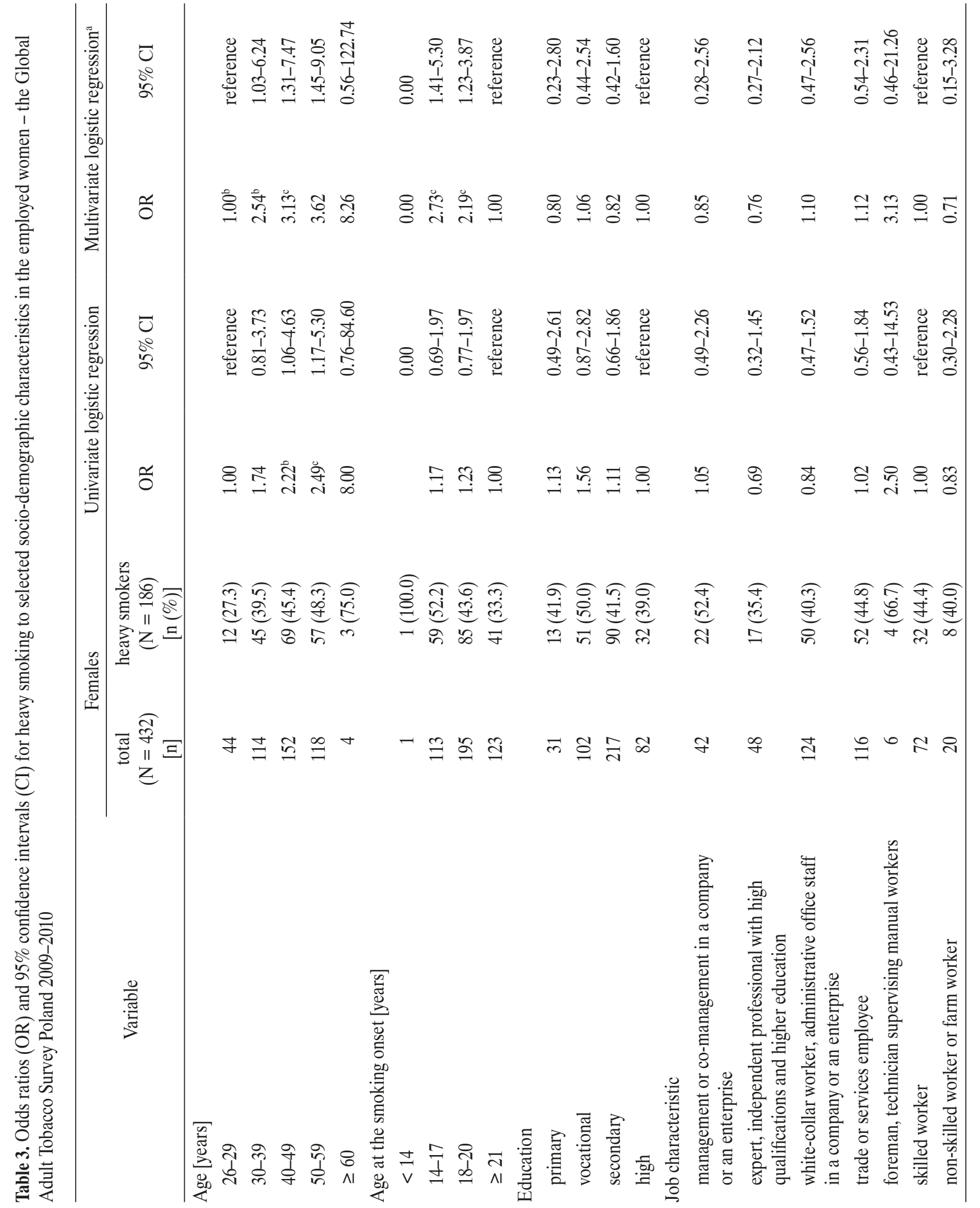




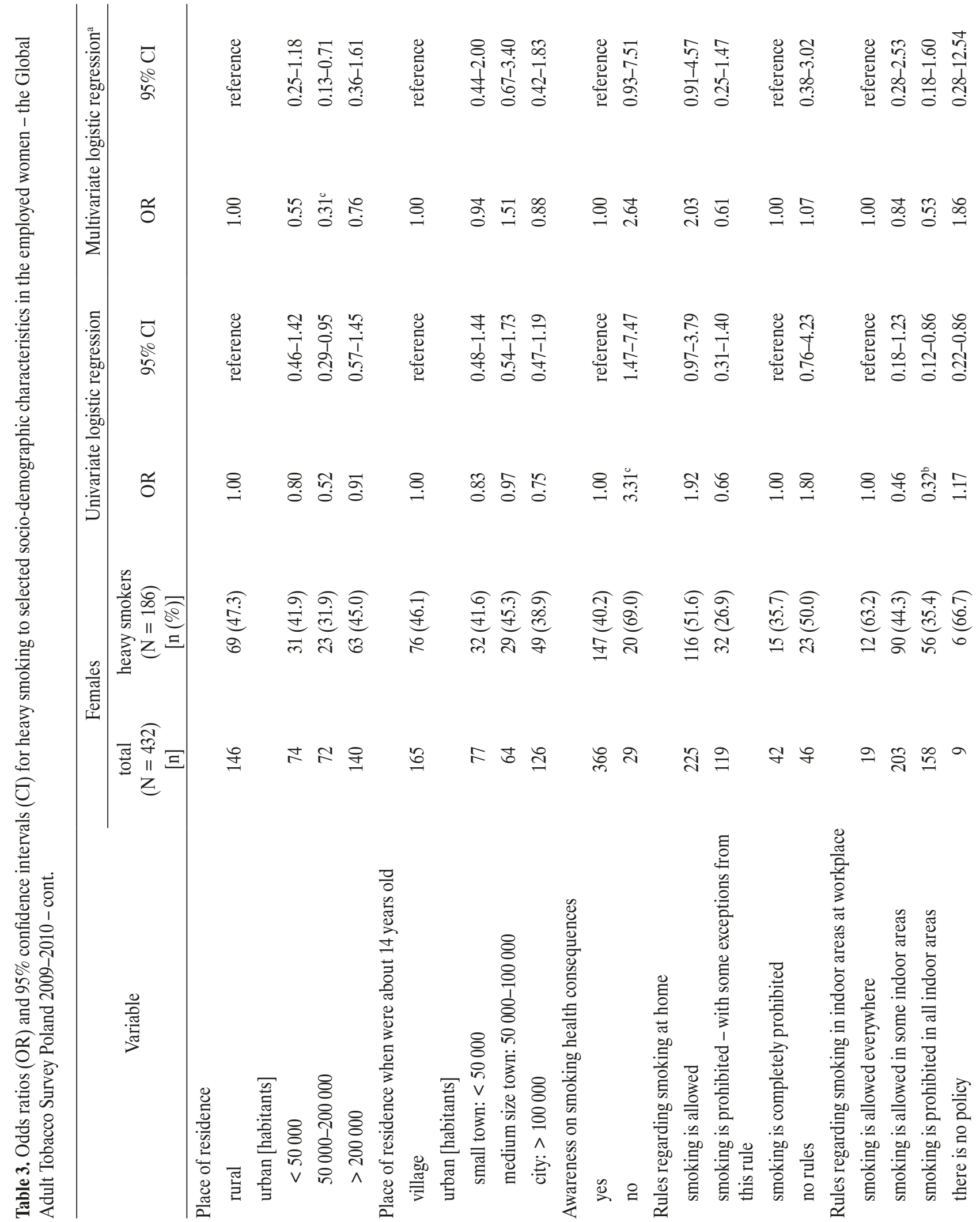




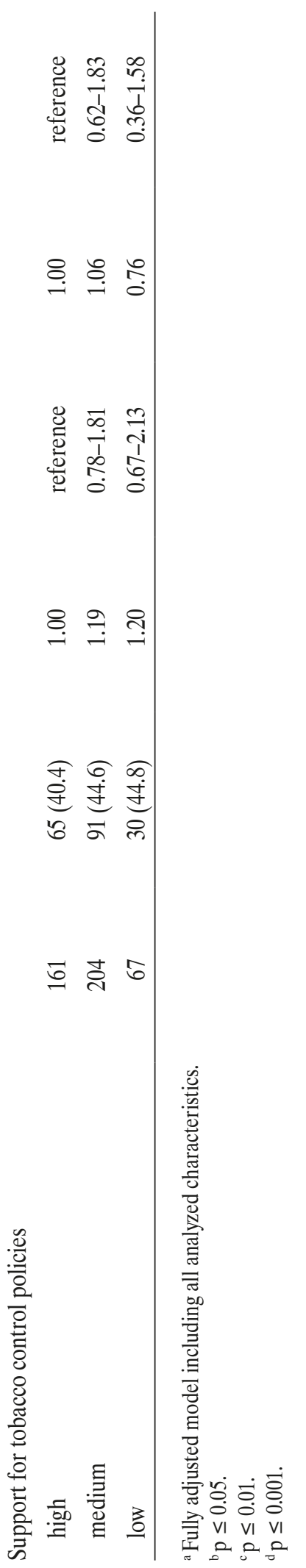

similarly to the men, the women who started smoking between the age 14-17 were 2.7 times more likely to be heavy smokers compared to those who started smoking after the age of $21(\mathrm{p}<0.01)$. Also, the women living in urban areas with a population between 50 000-200 000 had significantly lower odds of heavy smoking relative to those living in rural areas (OR $=0.3,95 \% \mathrm{CI}: 0.1-0.7, \mathrm{p}<0.001)$.

\section{DISCUSSION}

\section{Principal findings}

Similarly to other studies, we noticed significantly higher prevalence of heavy smoking among the men than among the women $[6,8]$. Nevertheless, we observed considerably higher rates of heavy smoking among Poles compared to the United States citizens. Among daily smokers represented in the employed population, the rate of heavy smokers was $63.5 \%$ in males and $43 \%$ in females, while in the studies by Wilson et al. $35 \%$ of men and $24 \%$ of women were classified as heavy smokers [20,21]. This difference can be caused by using different criteria to define heavy smokers, ethnic differences or different stages of tobacco epidemic in these countries. Moreover, in our analysis we only included economically active respondents age $\geq 26$ years. The report by Baumert et al. has displayed similar results [22].

Furthermore, results of our analysis correspond to the earlier reports suggesting that, heavy smokers compared with non-heavy smokers, are less likely to be represented in younger age groups [20,22]. The highest numbers of heavy level smokers were commonly found in the middle-age groups of the study respondents $[6,20,21]$. High prevalence of heavy smoking among older people is probably associated with difficulty in quitting smoking. The majority of smokers in our country want to quit smoking and many smokers try to quit. Also, a very small number of those who made a quit attempt used any aid (about 20\%), which could be ineffective, especially among heavy smokers [23]. It is remarkable that high 
rates of current smokers in Poland were not discussed with and advised to quit.

The study by Sorensen et al. has shown that, compared to non-heavy smokers, heavy smokers may depend more on nicotine and are more likely to respond to a broader range of cues to smoke, which are factors that seem to be associated with heavy smokers' bigger problems with quitting smoking [24]. Our results also indicated that heavy smokers were more likely to smoke their 1st cigarette of the day within 30 min from waking up, and wake up at night to smoke, which suggests that they were more nicotine dependent compared with lighter smokers.

The most common intervention doctors apply is to advise cessation (because it will prevent ill health), but it is offering support for smoking cessation (such as medication or behavioral support) that enhances the rate at which people attempt to stop smoking [23,25,26]. It has been estimated that total savings from benefit coverage (decreased healthcare and workplace costs) exceeded costs of the treatment within 4 years. Total savings per smoker ranged 350-582 dollars within 10 years and 1152-1743 dollars within 20 years. Internal rate of return ranged 39-60\% within 10 years of funding cessation via the workplace, but workplace-based smoking cessation programs are still uncommon in Poland [27]. However, many economically active people see a strong potential in such projects and would like to obtain support from their employers.

For instance, results from the Global Workplace Smoking Survey have shown that more than 2/3 of employers (69\%) and about $1 / 2$ of employees (48\%) indicated that their company should help employees with smoking cessation [18]. Employers and employees differed substantially regarding appropriate methods for encouraging cessation, with more employees favouring financial incentives and more employers favouring education. Both employees and employers value smoke-free workplace programs and workplace cessation support activities, although many would like their companies to offer more support $[9,18,27]$.
Approximately $2 / 3$ of employees and $81 \%$ of employers overall feel that smoke-free policies encourage cessation. In companies with smoke-free policies, $76 \%$ of employees and $80 \%$ of employers feel that their policy had been very, or extremely, effective in motivating employees to quit or reduce smoking [18].

Other studies have also found that totally smoke free workplaces are associated with reductions in the prevalence of smoking of 3.8\% (95\% CI: 2.8-4.7) and 3.1\% (2.4-3.8) fewer cigarettes smoked per day per a continuing smoker [28]. Combination of the effects of reduced prevalence and lower consumption per a continuing smoker yields a mean reduction of 1.3 cigarettes per day per an employee, which corresponds to a relative reduction of $29 \%$. It was estimated that if all workplaces became smoke free, consumption per capita in the entire population would drop by $4.5 \%$ in the United States and by $7.6 \%$ in the United Kingdom [28]. We also observed an association between implementation of total bans on smoking in indoor workplaces and lower odds of heavy smoking in the male population. The role of house rules that prohibited smoking should be also underlined. A complete ban on smoking at home was also associated with reduced odds of heavy smoking in men compared to those living in houses with no or partial bans.

In Poland there are some exceptions regarding smoking bans in the workplaces, e.g., bars or restaurants and other venues [29]. However, it is well known that partial bans are less effective than total bans. Implementation of a full smoking ban is associated with the largest decrease in second hand smoke exposure, while partial bans and changes in existing bans have inconsistent effects [30]. In addition to decreasing exposure in public places, as would be expected from legislation, bans may have additional benefits such as decreasing rates of current smokers and decreasing exposures to second hand smoke in private settings [30]. Unfortunately, it seems that there is still little knowledge on these facts. Furthermore, as the Global Workplace Smoking Survey has indicated, only $29 \%$ of employees believed 
that smoking had a negative financial impact on their company compared to $46 \%$ of employers. While almost $3 / 4$ of employees agreed that all workplaces should be smokefree, agreement was greater among employers (87\%) [31]. In our study early age at the onset of smoking (1417 years) was strongly associated with heavy smoking, by 3.3 (95\% CI: 2-5.5) multivariate odds of heavy smoking among the men and 2.7 (95\% CI: 1.4-5.3) among the women. Furthermore, it should be also noted that among the men, the higher job positions were associated with a lower likelihood of heavy smoking. These findings can be explained by an extended knowledge on health consequences of smoking, and different attitudes to their own health among the people from a higher social class with more education, compared to those with no such education and from lower social classes. It is suggested that higher education may increase awareness of benefits of healthy lifestyle, and improve individuals' ability to follow health education messages.

However, GATS has not shown statistically significant differences in this area among the women. This is worrisome because all the managers should be an example for their subordinates, have sufficient knowledge and motivation to be able to effectively participate in the implementation and enforcement of actions on tobacco control and protection from environmental tobacco smoke (ETS) in the workplace.

These results should be taken into consideration when developing prevention programs aimed at improving the health and health behavior change among the employed population.

\section{Study limitations and strengths}

Study limitations include recall bias, personal perception and the use of a cross-sectional study. The limitation of recall bias is evident in the self-reporting process of data collection. There are other methods that can be included in the survey data collection. For example biomarkers of tobacco smoking such as carbon monoxide could be included, but this incurs huge costs and more time, resulting in their occasional use for large surveys [32].

Other methods include collecting blood or saliva, which may increase the number of refusals to participate in the survey leading to the increased non-participation bias. In addition, tobacco metabolites have a short-half life in the body, making the assessment of biomarkers in the body valid only if evaluated right after collection [32]. Cross-sectional surveys tend to make observations at a single point in time. This leads to another study limitation, which is the inability to observe associations or determinants of heavy smoking among the economically active population over their life time.

On the other hand, questionnaire surveys are relatively cost-effective, they can be used for a relatively large population, and are a form of easy data collection. Questionnaires are also non-invasive. Moreover, confirming confidentiality can increase participation [32]. Well-constructed questionnaire surveys also tend to have high validity and reliability measures [22]. A meta-analysis of self-reported smoking studies suggested that self-reporting exhibits high levels of sensitivity and specificity [32]. Interviewer-administered questionnaires, such as GATS, produced higher values of sensitivity and specificity compared to self-administered questionnaires [33]. In addition, GATS is a nationally representative household survey of adults $\geq 15$ years of age. The program utilizes a uniform core questionnaire, sample design and collection procedures that have been inspected and accepted by international experts. Response rate from the program was over $60 \%$ of the average level compared with similar questionnaire surveys in Poland [33].

\section{CONCLUSIONS}

The Global Adult Tobacco Survey results have indicated that heavy smoking among the economically active population in Poland is a serious public health issue. According to GATS data, heavy smokers constitute over $1 / 2$ of 
daily smokers, with significantly higher prevalence of heavy smokers in males compared to females.

This study also identified characteristics associated with an increased risk of heavy smoking among the employed subjects in Poland. GATS has revealed that in Poland the tobacco control efforts to decrease the prevalence of heavy smoking and its consequences should be focused on the entire population of economically active Poles, but in particular, on the high risk subpopulations including male, older age, those who started to smoke at earlier age, blue collar employees, those who did not adopt smoke-free homes, respondents who are not protected by smoking bans in the workplace and the subjects from rural settings. Figures obtained from GATS show that implementation of smoke-free policies is very important and is associated with the reduced prevalence of heavy smoking.

Considering this, in terms of diminishing heaviness of smoking among economically active individuals, there is an urgent need to implement workplace based comprehensive tobacco control measures. One of the evidencebased strategies that should be considered is implementing complete smoking bans in the workplaces. Smoke free workplaces do not only protect nonsmokers from the dangers of passive smoking, but they also encourage smokers to quit or to reduce tobacco consumption [28]. Providing workplace smoking cessation programs should be also considered and may result in substantial health and economic benefits with economic savings exceeding the cost of the programs within a relatively short period of time [34-36]. In Poland, it seems that still little attention is paid to these issues, and there are many areas for improvement using well-known effective solutions and strategies [33,37].

\section{REFERENCES}

1. Eriksen M, Mackay J, Ross H. The tobacco atlas. 4th ed. Atlanta (GA): American Cancer Society, New York (NY): World Lung Foundation; 2012.
2. World Health Organization. Global status report on noncommunicable diseases 2010. Geneva: The Organization; 2011.

3. Peto R, Lopez AD, Boreham J, Thun M. Mortality from smoking in developed countries 1950-2010. 2nd ed. Oxford: Oxford University Press; 2004.

4. Bronnum-Hansen H, Juel K. Abstention from smoking extends life and compresses morbidity: A population based study of health expectancy among smokers and never-smokers in Denmark. Tob Control. 2001;10:273-8, http://dx.doi. org/10.1136/tc.10.3.273.

5. Nusselder WJ, Looman CWN, Marang-van de Mheen PJ, van de Mheen H, Mackenbach JP. Smoking and the compression of morbidity. J Epidemiol Community Health. 2000;54:566-74, http://dx.doi.org/10.1136/jech.54.8.566.

6. Klijs B, Mackenbach JP, Kunst AE. Obesity, smoking, alcohol consumption and years lived with disability: A Sullivan life table approach. BMC Public Health. 2011;11:378, http:// dx.doi.org/10.1186/1471-2458-11-378.

7. Bronnum-Hansen H, Juel K, Davidsen M, Sorensen J. Impact of selected risk factors on expected lifetime without longstanding, limiting illness in Denmark. Prev Med. 2007;45(1): 49-53, http://dx.doi.org/10.1016/j.ypmed.2007.03.010.

8. Haapanen-Niemi N, Miilunpalo S, Vuori I, Pasanen M, Oja P. The impact of smoking, alcohol consumption, and physical activity on use of hospital service. Am J Public Health. 1999;89(5):691-8, http://dx.doi.org/10.2105/AJPH. 89.5.691.

9. Halpern MT, Shikiar R, Rentz AM, Khan ZM. Impact of smoking status on workplace absenteeism and productivity. Tob Control. 2001;10:233-8, http://dx.doi.org/10.1136/tc.10.3.233.

10. Max W, Rice DP, Sung HY, Zhang X, Miller L. The economic burden of smoking in California. Tob Control. 2004;13: 264-7, http://dx.doi.org/10.1136/tc.2003.006023.

11. Tsai SP, Wen CP, Hu SC, Cheng TY, Huang SJ. Workplace smoking related absenteeism and productivity costs in Taiwan. Tob Control. 2005;14(Suppl 1):33-7, http://dx.doi. org/10.1136/tc.2003.005561. 
12. Parrot S, Godfrey C, Raw M. Costs of employee smoking in the workplace in Scotland. Tob Control. 2000;9:187-92, http://dx.doi.org/10.1136/tc.9.2.187.

13. Leigh JP, Fries JF. Disability in occupations in a national sample. Am J Public Health. 1992;82(11):1517-24, http:// dx.doi.org/10.2105/AJPH.82.11.1517.

14. Hammond EC. Evidence on the effects of giving up cigarette smoking. Am J Public Health Nations Health. 1965;55(5):682-91, http://dx.doi.org/10.2105/AJPH.55.5.682.

15. U.S. Department of Health and Human Services. The health consequences of smoking: A report of the surgeon general. Atlanta (GA): U.S. Department of Health and Human Services, Centers for Disease Control and Prevention, National Center for Chronic Disease Prevention and Health Promotion, Office on Smoking and Health; 2004.

16. Stewart WF, Ricci JA, Chee E, Morganstein D. Lost productive work time costs from health conditions in the United States: Results from the American Productivity Audit. J Occup Environ Med. 2003;45(12):1234-46, http://dx.doi. org/10.1097/01.jom.0000099999.27348.78.

17. Halpern MT, Taylor H. Beliefs regarding smoking in the workplace: Results from the Global Workplace Smoking Survey. Int J Public Health. 2009;54(6):391-401, http:// dx.doi.org/10.1007/s00038-009-0086-y.

18. Halpern MT, Taylor H. Employee and employer support for workplace-based smoking cessation: Results from an international survey. J Occup Health. 2010;52(6):375-82, http:// dx.doi.org/10.1539/joh.L10075.

19. The Maria Skłodowska-Curie Cancer Center and Institute of Oncology, Medical University of Warsaw, Centers for Disease Control and Prevention. Global Adult Tobacco Survey. Poland 2009-2010. Warszawa: Ministry of Health; 2010.

20. Wilson D, Wakefield M, Owen N, Roberts L. Characteristics of heavy smokers. Prev Med. 1992;21(3):311-9, http://dx. doi.org/10.1016/0091-7435(92)90030-L.

21. Wilson D, Taylor A, Roberts L. Can we target smoking groups more effectively? A study of male and female heavy smokers. Prev Med. 1995;24(4):363-8, http://dx.doi. org/10.1006/pmed.1995.1059.

22. Baumert J, Ladwig KH, Ruf E, Meisinger C, Döring A, Wichmann HE. Determinants of heavy cigarette smoking: Are there differences in men and women? Results from the population-based MONICA/KORA Augsburg Surveys. Nicotine Tob Res. 2010;12(12):1220-7, http://dx.doi. org $/ 10.1093 /$ ntr/ntq172.

23. Sieminska A, Buczkowski K, Jassem E, Lewandowska K, Ucinska R, Chelminska M. Patterns of motivations and ways of quitting smoking among Polish smokers: A questionnaire study. BMC Public Health. 2008 Aug 4;8:274, http://dx.doi. org/10.1186/1471-2458-8-274.

24. Sorensen G, Goldberg RJ, Ockene JK, Klar JM, Tannenbaum T, Lemeshow S. Heavy smoking among a sample of employed women. Am J Prev Med. 1992;8:207-14.

25. Zhu SH, Lee M, Zhuang YL, Gamst A, Wolfson T. Interventions to increase smoking cessation at the population level: How much progress has been made in the last 2 decades? Tob Control. 2012;21:110-8, http://dx.doi.org/10.1136/tobaccocontrol-2011-050371.

26. World Health Organization. The current status of the tobacco epidemic in Poland. Copenhagen: The Organization; 2009.

27. Halpern MT, Dirani R, Schmier JK. Impacts of a smoking cessation benefit among employed populations. J Occup Environ Med. 2007;49(1):11-21, http://dx.doi.org/10.1097/ JOM.0b013e31802db579.

28. Fichtenberg CM, Glantz SA. Effect of smokefree workplaces on smoking behaviour: Systematic review. BMJ. 2002; 325:1-7, http://dx.doi.org/10.1136/bmj.325.7357.188.

29. [The Act of 9 November 1996 on the protection of health against the consequences of the use of tobacco and tobacco products. J Laws 1996, No. 10, item 55]. Polish.

30. Naiman AB, Glazier RH, Moineddin R. Is there an impact of public smoking bans on self-reported smoking status and exposure to secondhand smoke? BMC Public Health. 2011;11:146, http://dx.doi.org/10.1186/1471-2458-11-146. 
31. Lundborg P. Does smoking increase sick leave? Evidence using a register data on Swedish workers. Tob Control. 2007;16:114-18, http://dx.doi.org/10.1136/tc.2006.017798.

32. Patrick DL, Cheadle A, Thompson DC, Diehr P, Koepsell T, Kinne $S$. The validity of self-reported smoking: A review and meta-analysis. Am J Public Health. 1994;84:1086-93, http:// dx.doi.org/10.2105/AJPH.84.7.1086.

33. World Health Organization. WHO report on the global tobacco epidemic. Implementing smoke-free environments. Geneva: The Organization; 2009.

34. Bauer JE, Hyland A, Li Q, Steger C, Cummings KM. A longitudinal assessment of the impact of smoke-free policies on tobacco use. Am J Public Health. 2005;95(6):1024-9, http://dx.doi.org/10.2105/AJPH.2004.048678.

35. Bondi MA, Harris JR, Atkins DA, French ME, Umland B. Employer coverage of clinical preventive services in the United States. Am J Health Promot. 2006;20(3):214-22, http://dx.doi.org/10.4278/0890-1171-20.3.214.

36. Bunn WB, Stave GM, Downs KE, Alvir JMJ, Dirani R. Effect of smoking on productivity loss. J Occup Environ Med. 2006;48(10):1099-108, http://dx.doi.org/10.1097/01. jom.0000243406.08419.74.

37. World Health Organization. WHO framework convention on tobacco control. Geneva: The Organization; 2003.

This work is available in Open Access model and licensed under a Creative Commons Attribution-NonCommercial 3.0 Poland License - http://creativecommons.org/ licenses/by-nc/3.0/pl/deed.en. 